\title{
BMJ Open Maintenance of non-pharmacological strategies 6 months after patients with chronic obstructive pulmonary disease (COPD) attend a breathlessness service: a qualitative study
}

Tim Luckett (10 , ${ }^{1}$ Mary Roberts, ${ }^{2,3,4}$ Vinita Swami, ${ }^{3}$ Tracy Smith, ${ }^{3,4}$ Jin-Gun Cho,,${ }^{2,3,4}$ Ester Klimkeit, ${ }^{3}$ John R Wheatley ${ }^{2,3,4}$

To cite: Luckett T, Roberts M, Swami V, et al. Maintenance of non-pharmacological strategies 6 months after patients with chronic obstructive pulmonary disease (COPD) attend a breathlessness service: a qualitative study. BMJ Open 2021;11:e050149. doi:10.1136/ bmjopen-2021-050149

- Prepublication history for this paper is available online. To view these files, please visit the journal online (http://dx.doi org/10.1136/bmjopen-2021050149).

Received 16 February 2021

Revised 28 April 2021

Accepted 29 April 2021
Check for updates

(C) Author(s) (or their employer(s)) 2021. Re-use permitted under CC BY-NC. No commercial re-use. See rights and permissions. Published by BMJ.

For numbered affiliations see end of article.

Correspondence to

Dr Tim Luckett;

tim.luckett@uts.edu.au

\section{ABSTRACT}

Objectives This study aimed to explore the degree to which non-pharmacological strategies for chronic breathlessness are sustained 6 months after completing a breathlessness service in patients with chronic obstructive pulmonary disease (COPD), and patient perceptions regarding the need for ongoing support.

Design A qualitative approach was taken using semistructured telephone interviews. Thematic analysis used an integrative approach.

Setting The Westmead Breathlessness Service (WBS) trains patients with COPD to self-manage chronic breathlessness over an 8-week programme with multidisciplinary input and home visits.

Participants Patients with moderate to very severe COPD who had completed the WBS programme 6 months earlier. Results Thirty-two participants were interviewed. One or more breathlessness self-management strategies were sustained by most participants, including breathing techniques $(n=22 ; 69 \%)$, the hand-held fan $(n=17$; $53 \%)$, planning/pacing and exercise $(n=14$ for each; $44 \%)$ and strategic use of a four-wheeled walker $(n=8$; $25 \%$ ). However, almost a third of participants appeared to be struggling psychologically, including some who had refused psychological intervention. A 'chaos narrative' appeared to be prevalent, and many participants had poor recall of the programme.

Conclusions Self-management strategies taught by breathlessness services to patients with moderate to very severe COPD have potential to be sustained 6 months later. However, psychological coping may be more challenging to maintain. Research is needed on ways to improve resilience to set-backs and uptake of psychological interventions, as well as to understand and address the implications of poor recall for self-management. Trial registration number ACTRN12617000499381

\section{INTRODUCTION}

Chronic breathlessness is a debilitating syndrome in people with chronic obstructive pulmonary disease (COPD) that persists despite optimised, guideline-concordant

\section{Strength and limitations of this study}

- This is the first study to examine 6-month maintenance of non-pharmacological strategies learnt through a breathlessness service, and to focus on a breathlessness service developed specifically for patients with chronic obstructive pulmonary disease (COPD).

- The focus on patients with COPD is both a strength and limitation, enabling an in-depth understanding of challenges faced by this patient population but limiting generalisability to other populations who may benefit from breathlessness services.

- Problems with recall shown by many participants limited the richness of interview data for qualitative analysis.

pharmacological treatment of the underlying medical condition(s). ${ }^{1}$ Although chronic breathlessness cannot be cured, it can be managed with both non-pharmacological and pharmacological therapies aimed at modulating the perception of breathlessness and the individual's response. ${ }^{2}$ These therapies are ideally delivered within a selfmanagement framework in which people learn skills to reduce the impact on functioning and to sustain their emotional wellbeing. ${ }^{3}$

The 'breathlessness service' has emerged as a new model of care for chronic breathlessness in which expert multidisciplinary teams train patients to self-manage using a range of non-pharmacological therapies, including breathing techniques, exercise/physical activity, planning and pacing, a hand-held fan and relaxation strategies. ${ }^{5}$ Clinical trials have identified benefits to breathlessnessrelated distress and depression and, to a lesser degree, breathlessness mastery and 
severity, and anxiety. ${ }^{67}$ Qualitative substudies from these trials have found that many participants reported benefits from reduced panic and increased confidence even when quantitative results for distress due to breathlessness and anxiety/depression were not significant. ${ }^{8}$ However, no study to date has examined whether patients' use of the non-pharmacological strategies and related benefits are sustained beyond the immediate intervention period.

This study aimed to explore the degree to which nonpharmacological strategies and patient-perceived benefits were sustained 6 months after completing a breathlessness service designed for patients with moderate to very severe COPD, as well as patient perceptions regarding the need for ongoing support.

\section{METHODS}

The subjective, multidimensional nature of chronic breathlessness warranted a qualitative approach. Reporting of the study has been guided by the Consolidated Criteria for Reporting Qualitative Research. ${ }^{9}$ All participants gave written informed consent to participate.

\section{Setting}

The study focused on a breathlessness service in Western Sydney, Australia. The Westmead Breathlessness Service (WBS) is run over 8 weeks (plus preassessments and postassessments) through a respiratory medicine outpatient service at a metropolitan hospital providing tertiary and quaternary services to a socioeconomically and culturally diverse population. The WBS offers multidisciplinary support from a physician, two nurses, a physiotherapist, an occupational therapist and dietitian, providing both outpatient and in-home individualised sessions. To be eligible for the WBS, patients need to have moderate to very severe COPD (defined as forced expiratory volume in $1 \mathrm{~s}\left(\mathrm{FEV}_{1}\right) /$ forced vital capacity $\leq 70 \% ; \mathrm{FEV}_{1} \leq 60 \%$ predicted), moderate to severe breathlessness (Modified Medical Research Council Dyspnoea Scale ${ }^{10}$ score $\geq 2$ ), and be assessed as willing and able to actively participate in their own care by the WBS team. ${ }^{11}$ Patients are referred to the WBS by respiratory specialists, general practitioners, nurses and allied health personnel. Previous attendance at pulmonary rehabilitation is encouraged, but patients who were unable to attend for various reasons are still eligible for referral. After completing the programme, patients are encouraged to contact the WBS again by telephone whenever they require further support. Patients who are identified by standardised screening as being at risk for depression and/or anxiety at the end of the initial 8-week programme, and who accept referral, are seen by a psychologist for six to eight sessions of cognitive behavioural therapy (CBT) over a 10 -week period. Patients may also be visited by a member of the WBS team if they are admitted to Westmead Hospital and the WBS team becomes aware of their admission.

Recruitment for a randomised controlled trial evaluating WBS is currently underway, with the primary endpoint being mastery of breathlessness as measured by the Chronic Respiratory Questionnaire. ${ }^{12}$ A detailed protocol has recently been published. ${ }^{11}$ For the trial, patients are followed up by telephone 3 and 6 months after they complete the WBS programme for outcome measurement by a WBS trials nurse who is not involved in their care. This article reports on results from the 6-month follow-up time-point of the trial's qualitative substudy. Results from the first time-point of the qualitative substudy $(n=41)$ have been reported elsewhere and focused on patient perceptions of benefits derived from the service and ideas for improvement. ${ }^{13}$

\section{Sample}

Participants were drawn from consecutive patients who completed the WBS programme between June 2017 and September 2019 and had been interviewed at the first time-point. The sample size for the first time-point was determined by 'information power'. ${ }^{14}$ For the second time-point, we interviewed everyone in the initial sample who agreed to be interviewed again and could be contacted.

\section{Data collection}

Semistructured interviews were conducted by telephone approximately 6 months after completing the WBS programme. Questions focused on participant perceptions regarding their overall health status compared with when they completed the programme; the degree to which they were still using the strategies they learnt through the WBS and deriving benefit from them and considerations regarding continued contact with the WBS. Interviews were conducted by a male social scientist with experience in qualitative research (TL), who was employed as a university academic and had no previous or continuing relationships with participants other than conducting the initial interview following WBS completion. We explained to participants that our research was aimed at improving the WBS for future patients. Interviews were audio-recorded and field notes were made. Data were transcribed and managed using NVivo V.12 software (QSR International).

To provide context, data were extracted from patients' medical records regarding contact with the WBS since the time of their first interview, as well as from the trial dataset on participant age, living alone status, use of longterm oxygen therapy, attendance at pulmonary rehabilitation, and performance on a range of clinical tests and measures of breathlessness, anxiety and depression.

\section{Analysis}

Thematic analysis used an integrative method designed for informing the development of health service interventions. ${ }^{15}$ This method uses both inductive and deductive approaches to build on previous research while remaining open to new insights. The initial coding structure was defined by the study's aims and interview questions. It was decided that coding of interviews would 
benefit from both WBS 'insider' and 'outsider' perspectives to reduce confirmation bias while also ensuring that interpretations were informed by a deep understanding of the service. Analyses were therefore conducted independently by two researchers who then met to discuss any disagreements: TL and a female respiratory clinical nurse consultant involved in delivering the WBS (MR or VS). As well as being analysed thematically, each transcript was rated by two independent reviewers (TL and MR or VS) for whether the participant reported their overall health status to be better, worse or unchanged compared with when they complete the programme, taking into account the entire interview. Neither transcripts nor emerging themes were returned to participants for verification.

\section{RESULTS}

Thirty two of the $41(78 \%)$ participants who were interviewed at the first time-point were interviewed at the second time-point. Of the original sample, 15/18 participants who reported 'significant' benefit at the first timepoint participated, 13/17 who reported 'some' benefit, $2 / 2$ who reported 'no' benefit and 2/4 who were difficult to code were interviewed for this study. Nine of the original participants were not re-interviewed; four patients could not be contacted despite multiple attempts by telephone, three had died in the intervening period, and two refused, one of whom cited poor health as the reason. Interviews took place at a median of 194 days following

Table 1 Participant characteristics $(n=32)$

\section{Characteristic (summary measure)}

\begin{tabular}{|c|c|}
\hline Age (years) & $70.6(6.6)$ \\
\hline Male (\%) & 61 \\
\hline Lives alone (\%) & 39 \\
\hline Long-term oxygen therapy (\%) & 12 \\
\hline Completed PR within past year (\%) & 36 \\
\hline $\mathrm{FEV}_{1}(\mathrm{~L})$ & $0.82(0.32)$ \\
\hline $\mathrm{FEV}_{1}$ (predicted) & $31(12)$ \\
\hline VC (L) & $2.32(0.76)$ \\
\hline VC (\% predicted) & $66(15)$ \\
\hline $\mathrm{FEV}_{1} \mathrm{NC}(\%)$ & $36(12)$ \\
\hline 6MWD (m) & $304(95)$ \\
\hline mMRC (points) & $3.5(0.92)$ \\
\hline Breathlessness NRS on exertion (points) & $7.9(1.7)$ \\
\hline $\begin{array}{l}\text { HADS anxiety and/or depression scores }>7 \\
(\%)\end{array}$ & 56 \\
\hline
\end{tabular}

Data are presented as mean (SD), or \% total group. $\mathrm{FEV}_{1}$, forced expiratory volume in one second; HADS, Hospital Anxiety and Depression Scale (with scores $>7$ suggestive of symptoms in the clinical range); mMRC, modified Medical Research Council Dyspnoea Scale (0-4); 6MWD, 6-minute walk distance; NRS, 0-10 Numerical Rating Scale for severity; PR, pulmonary rehabilitation; VC, vital capacity. the first interview (IQR, 188-210 days) and ranged from $6 \mathrm{~min}$ to $36 \mathrm{~min}$ in length. See table 1 for participant characteristics.

Compared with when they had completed the WBS programme, four participants were rated by researchers after reading their entire transcript as reporting their overall health status to be better $(12.5 \%)$, four unchanged $(12.5 \%)$ and eight worse (25\%). The remaining 16 participants $(50 \%)$ were either uncertain about their change in health status or else made contradictory statements that cast doubt on the reliability of their reporting. The four participants who reported improved health status each attributed this to a different reason, including consistent exercise, change in medication, surgical intervention or unknown factors. Several of those who reported themselves to be worse attributed this to a recent chest infection or health conditions other than COPD. Roughly one in five participants had been hospitalised since completing the WBS programme from either COPD or another health condition, in equal proportions. For two participants, COPD was reported to be of lesser concern compared with cataracts and heart disease, respectively.

\section{Contact with the WBS and desire for further support}

Electronic medical record data identified that 24 participants $(75 \%)$ had been in contact with the WBS since the time of their first interview for reasons outside the research protocol mentioned above, 11 (34\%) of whom initiated the contact and $13(41 \%)$ of whom were contacted for follow-up by the WBS, including two who were seen while admitted to hospital. Nine participants were seen by the WBS psychologist. Six of the eight participants who did not have contact with the WBS had been seen by one or more of its affiliated services. Only two of the 32 participants interviewed had received no contact with WBS or its affiliated services since completing the programme.

Many participants lacked a clear memory of contacts with the WBS vis-à-vis other services, or which support they had received from each.

P23: I did better with it [hand-held fan] than not, so I went and bought one.

Interviewer: Right. So that was the Westmead Clinic that put you on to that in the first place?

P23: No ... I don't know. (P23, man in his mid 50s)

However, when prompted, most participants appeared to remember individual personnel at the WBS and repeated comments they had made at their initial interview regarding their caring and supportive approach. When asked, all participants also expressed a belief that they could contact the WBS again for support whenever they needed to.

I know they're there if I needed to call. (P21, woman in her late 60s)

The most common reason for not having initiated contact with the WBS was a belief that the service had 
provided all the support it could and further contact would not be beneficial. Some participants expressed this in terms of feeling confident in self-managing their breathlessness without further assistance, whereas others framed it as themselves having given up on finding new ways to improve their ability to live with COPD.

They've given me all the tools. I know what to do, you know what I mean? (P12, woman in her late 60s)

I don't feel it's sort of getting any progress with it really. That's the best way I can put it. (P16, woman in her early 80 s)

One of the participants who still used strategies she had learnt from the WBS indicated that the written information she had been given by the service reduced the need for further contact.

Sometimes I forget [the breathing techniques]. But then I just go to the programme thing that they gave me and I just do it. (P32, woman in her mid 70s)

\section{Sustainability}

All except two participants identified specific strategies taught through the WBS that they still used to selfmanage their breathlessness. Interestingly, this included one of two participants who had self-reported no benefit from the WBS when interviewed at the first time-point but who reported continuing use of breathing techniques, the hand-held fan, exercise, planning and pacing, and techniques for helping with showering at the 6-month time-point; this participant was also among those whose reports of overall change were deemed inconsistent when the entire transcript was rated by researchers. The other participant who had reported no benefit at the first time-point was among those who had not sustained any strategies, and now indicated that he was in the end-oflife phase. The second participant who did not report continuing use of any strategies appeared to have poor memory of the WBS and interviewer.

Among the strategies sustained, breathing techniques were in use by the largest number of participants $(n=22$; $69 \%)$, followed by the hand-held fan $(\mathrm{n}=17 ; 53 \%)$, planning/pacing and exercise ( $\mathrm{n}=14$ for each; $44 \%)$ and strategic use of a walker $(\mathrm{n}=8 ; 25 \%)$, with two participants continuing sputum clearing techniques.

I got that [the hand-held fan] from the girls in the clinic ... I have fans in every room, the little hand fans. I have one in my shopping bag in case I go to my daughter's or somewhere. I always have one in my bag. I've got one in the bedroom, one in the little lounge room, and out in the courtyard. So, I've got a fan near me whenever I need it. (P02, woman in her mid 80s)

\section{Psychological coping}

Participants were especially divided on the degree to which they had sustained psychological benefits they had reported at the first interview. Almost a third of participants reported problems with psychological coping. These participants included patients whose health status was unchanged and those who had declined in roughly equal proportions. Psychological challenges were typically described in terms of a difficulty with persevering over the long-term in the face of relentless breathlessness and impacts on daily life. This included the challenge of maintaining behaviour change over time and coping with relapse.

Yeah, and it's this frustration. What I'm doing is not helping me. It is helping me out in combating it all, as the girls [from the WBS] have taught me, and that. And that does help, but it doesn't get rid of the constants of it all because I know as soon as I move it's back again ... But then I go and start smoking ... And then I regret that 'cause then I burn, I can't breathe at all, so back to the drawing board again. Then I start out and I get strong again and then it doesn't last and then I get downhearted again. And it's like a big circle I'm putting myself in, you know? (P04, man in his mid 60s)

In other cases, a loss in confidence was associated with a specific event, usually a chest infection and hospitalisation.

I was in the actual hospital. About 5 weeks ago now. And I've come good since but very gingerly ... had a chest infection, I had a friend come to stay with a bloody cold ... So I've been on major antibiotics since - medications, yeah, not easy ... I just don't have as much energy. I don't eat like I used to, my taste buds are gone to, I don't know, have gone south somewhere. Little things, my mobility is not the same. (P20, man in his early 60s)

This contrasted with a similar proportion of participants who reported themselves to be coping relatively well psychologically. While some participants were able to attribute this to perceived improvements in their general health, others referred to positive attitude or persistence in the face of little change or even decline.

I've still got my positive attitude and outlook; I'm not going to rest on my laurels, no. As I've been told by all and sundry, it'll never sort of get back to what it was, but just the quality of life - that's my main purpose in life at the moment, yeah. (P31, man in his early 70s)

\section{Psychological intervention}

Three participants reported that they had received support from the WBS psychologist in the intervening 6 months. Two of these perceived that their selfmanagement of anxiety had improved through learning relaxation and cognitive behavioural strategies; the third reported limited benefit.

She [the psychologist] was nice to talk to you, but I mean, I'm at the stage now where I don't know if 
anyone can really help that much, can they? That sounds a bit... I know it sounds like I'm feeling sorry for myself, but I'm being realistic. What can I do? (P25, woman in her early 70s)

Four more participants who had been expecting to see the psychologist when interviewed at the first timepoint reported deciding against this either because they didn't believe it could assist them $(n=3)$ or believed that they didn't need it anymore $(n=1)$. Two participants highlighted the deep-rooted nature of their psychological challenges, and one also expressed a reluctance to disclose and explore potentially contributory distressing experiences, sometimes in early life.

There's some very personal stuff that's in my life, you know. (P07, man in his early 60s)

Several participants also referred to stigma and suspicion as barriers to accepting a psychology referral, including one man who had overcome this and benefitted.

One of the first things you say is 'you're not psychologically profiling me here at the minute are you?' Some FBI you know? ... like they said, 'it's going to be an intervention', and the word 'intervention' to old people feels like they're going to get locked up put in a home! (P38, man in his early 60s)

\section{DISCUSSION}

This study extends previous qualitative research on the nature of benefits that patients perceive from attending breathlessness services ${ }^{81316}$ by exploring the sustainability of self-management strategies and benefits 6 months afterwards in patients with moderate to very severe COPD. Most patients were continuing to use nonpharmacological strategies they had learnt at the WBS. However, almost a third of participants were found to be struggling psychologically. These patients appeared to have been showing reductions in what has been termed 'breathing space', demonstrated through disengaged coping and a disinclination to seek help. ${ }^{17}$

Despite maintenance of psychological coping being an area of challenge, four patients had declined referral to a psychologist. This is consistent with the literature suggesting that around a third of eligible patients with COPD refuse $\mathrm{CBT},{ }^{18}$ with attrition rates of around $55 \% .^{19}$ Our study follows at least one other ${ }^{20}$ in finding this to be partly attributable to a lack of perceived need for psychological intervention arising from a belief that intervention will be futile or else that symptoms may not be severe enough to warrant assistance. Mistrust of psychologists and a reluctance to delve into personal histories were also barriers within the current sample. Recent research has increasingly focused on improving uptake of pulmonary rehabilitation by people with $\mathrm{COPD},{ }^{21}$ but less so psychological intervention. Given evidence that CBT improves anxiety and depression in patients with COPD compared with usual care, ${ }^{22}$ more focus is needed on improving uptake through de-stigmatising mental health treatment among this older population and providing patient education aimed at helping patients to better understand: (1) the detrimental impact of mood on selfmanagement; (2) ways in which psychological intervention may be useful for managing chronic conditions and (3) differences between CBT and psychoanalysis; i.e. that the former focuses on making explicit and reframing less helpful thoughts, while the latter has a greater emphasis on delving into childhood history and making the unconscious conscious.

The poor memory and confusion shown by many participants in this study regarding their health status over time is consistent with previous evidence that mild cognitive impairment is common in people with COPD. ${ }^{23}$ Recall problems were extensive and pervasive throughout many interviews. In some cases, participants struggled to distinguish the WBS from other services or even to recall the WBS at all. This was especially surprising given participants' praise for individual WBS personnel and strong therapeutic relationships reported in the initial interviews. ${ }^{13}$ Findings from our study on patients with COPD differs from research that has examined long-term maintenance of self-management education in patients with other chronic illnesses such as diabetes, ${ }^{24}{ }^{25}$ none of which identified poor memory to be an important barrier to sustaining strategies despite finding other challenges (although these samples were significantly younger than our cohort, potentially accounting for some of the observed difference). If patients cannot recall changes in their recent health, they may also struggle to recall important health management activities (eg, complex medication regimens necessary to manage multiple comorbidities). The cognitive demand of CBT may also pose a barrier to people with cognitive impairment unless specific attention is given to modifying delivery. ${ }^{26}$ Further research is needed to integrate existing evidence-based recommendations that support people with cognitive impairment with strategies for self-managing chronic breathlessness.

The narratives told by our participants appeared similar to those of patients with COPD in a previous qualitative study by Pinnock et al ${ }^{27}$ which found 'chaos' to be the prevailing characteristic. Pinnock et al built on work by Frank $^{28}$ in identifying three illness narratives: a restitution narrative ("yesterday I was healthy, today I am sick, but tomorrow I will be healthy again"); a quest narrative ("I have a health problem but I'm using the experience to improve the situation [for myself or others]" and a chaos narrative ("this happened. Later on this happened. And also this happened') (p3). ${ }^{27}$ Although all three of these narratives were evident in our findings, the chaos narrative was especially prevalent. Like patients in Pinnock $e t a l \mathrm{~s}^{27}$ sample, many participants in our study seemed to view the burden from COPD as a 'way of life' (p4), rather than as a stressor over which they retained control concerning their emotional response and impact on functioning. In 
both studies, a chaos narrative was manifest as a sense of disempowerment in general and reduced self-efficacy for self-managing in particular. Participants needed repeated prompting to consider how self-management influenced their experience of living with breathlessness rather than default to more passively attributing impacts entirely to their disease. Their reports also tended to be fragmented rather than coherent and linear.

Educational and coaching intervention studies have commonly focused on improving self-efficacy as a prerequisite for self-management skills in people with COPD, ${ }^{29} 30$ with a small number demonstrating sustained improvements over 6 months ${ }^{31}$ or even a year. ${ }^{32}$ However, such studies have rarely controlled for the degrees to which participants are self-efficacious at commencement, or attempted a 'second dose' to boost self-efficacy at follow-up in patients who have only partially or not responded. It seems likely that patients may be more or less predisposed to respond to self-management interventions depending on a range of psychological attributes that have been conceptualised variously as locus of control, ${ }^{33}$ readiness for change ${ }^{34}$ and dispositional coping style. ${ }^{35}$ 'Activating' a patient to become engaged in self-management may require a process that involves helping them: '(1) to believe the patient role is important; (2) have the confidence and knowledge necessary to take action; (3) actually take action to maintain and improve one's health and (4) stay the course even under stress' (p1005) ${ }^{36}$ This study suggests that some patients who appear to make initial gains on the first three stages of activation may struggle to maintain the fourth. Greater attention may be needed to coach patients on the likelihood that they will face set-backs/relapses, together with practical strategies for remaining resilient. Further research is also required to evaluate whether booster self-management interventions for people who relapse offer a 'high return on investment' or a 'diminishing return'. In a study that provided CBT-based 'stepped care' for anxiety and depression, most participants rejected the offer of further treatment when their symptoms recurred. ${ }^{20}$ However, neither this study nor many other CBT trials in COPD have measured patient self-efficacy. ${ }^{22}$ More research is needed on the complex and multidirectional relationships between the various constructs thought to underpin patients' capacity to derive benefit, as well as the nature of difficulties faced by patients with severe COPD in sustaining psychological gains and self-management-for example, whether this is akin to 'demoralisation syndrome', which may require a dedicated management approach. ${ }^{37}$

This study has several strengths and weaknesses. The sample who provided interview data at 6-month follow-up in this study were drawn from a consecutive patient population recruited to provide 'information power ${ }^{14}$ at the first time-point. ${ }^{13}$ Although there was $22 \%$ attrition between timepoints, participants lost to follow-up did not appear to be biased towards those who reported greater or lesser benefit initially. The most important limitation of this study pertained to negative impacts on data quality of participants' poor recall, potentially attributable to cognitive impairments and chaos narrative, as described above. Participants' recollection of their contact with the WBS may have been complicated by the fact that some WBS staff also worked in affiliated services, such as the COPD Integrated Care Service and Respiratory Ambulatory Care Service. Also, interviewing by telephone limits non-verbal communication that might have served as additional cues for participant memory and enabled the interviewer to better assess whether participants were seeking to disguise memory loss, contributing to the richness of data. However, the interviewer was not involved in care so would have been unlikely to trigger recall of the service, and faceto-face interviews would not have been possible during the COVID-19 pandemic. Even after Australia was successful in controlling community cases, participants with respiratory disease were keen to maintain social isolation, and in-person contact was discouraged for research purposes. Although video conferencing could have been considered, some older participants have refused this option in our previous studies, leading to an inconsistent approach to data collection across participants. Using a qualitative approach, this study sought to give patients a 'voice', but no consumers were involved as coresearchers, and analysis used a professional 'lens'. Finally, the WBS is the first breathlessness intervention service to be evaluated that specifically targets patients with COPD rather than a mixture of malignant and non-malignant diagnoses. ${ }^{67}$ This limits generalisability of our findings to other patient populations but also enabled a more finely grained consideration of COPD-specific issues.

In conclusion, this study builds on previous research to suggest that most patients with COPD who attend a breathlessness service continue to use at least some strategies 6 months afterwards. Maintenance of psychological coping appears to be more challenging and may occur within the context of attitudinal barriers to accepting psychological intervention along with challenges of behaviour change. Further research is needed to understand interactions between poor memory, cognitive decline and psychological coping, and the impact these may have on sustaining self-management.

\section{Author affiliations}

${ }^{1}$ Improving Palliative, Aged and Chronic Care through Clinical Research and Translation (IMPACCT), Faculty of Health, University of Technology Sydney, Sydney, New South Wales, Australia

${ }^{2}$ Ludwig Engel Centre for Respiratory Research, Westmead Institute for Medical Research, Westmead, New South Wales, Australia

${ }^{3}$ Department of Respiratory and Sleep Medicine, Westmead Hospital, Westmead, New South Wales, Australia

${ }^{4}$ The University of Sydney at Westmead Hospital, Westmead, NSW, Australia

Contributors All authors except VS contributed to the conceptualisation and design of the randomised controlled trial of which the reported research is a qualitative substudy. TL, MR, VS, TS and JRW: designed the qualitative substudy. TL: conducted the interviews. TL, MR and VS: conducted initial line-by-line coding of the transcripts, with additional input to thematic analysis provided by TS. All authors contributed to interpretation of the results and writing of the manuscript, with additional unique intellectual contributions provided by J-GC and EK.

Funding This study was funded by a New South Wales Health Translational Research Grant (number 113).

Competing interests None declared. 
Patient and public involvement Patients and/or the public were not involved in the design, or conduct, or reporting, or dissemination plans of this research.

Patient consent for publication Not required.

Ethics approval Ethics approval was provided by the Human Research Ethics Committee at Westmead Hospital, Sydney, Australia.

Provenance and peer review Not commissioned; externally peer reviewed.

Data availability statement No data are available. To protect the identity of participants, interview transcripts cannot be made available. However, the thematic coding structure is available on request.

Open access This is an open access article distributed in accordance with the Creative Commons Attribution Non Commercial (CC BY-NC 4.0) license, which permits others to distribute, remix, adapt, build upon this work non-commercially, and license their derivative works on different terms, provided the original work is properly cited, appropriate credit is given, any changes made indicated, and the use is non-commercial. See: http://creativecommons.org/licenses/by-nc/4.0/.

ORCID iD

Tim Luckett http://orcid.org/0000-0001-6121-5409

\section{REFERENCES}

1 Johnson MJ, Yorke J, Hansen-Flaschen J, et al. Towards an expert consensus to delineate a clinical syndrome of chronic breathlessness. Eur Respir J 2017;49:1602277. doi:10.1183/13993003.02277-2016

2 Johnson MJ, Currow DC. Chronic refractory breathlessness is a distinct clinical syndrome. Curr Opin Support Palliat Care 2015:9:203-5.

3 Lorig KR, Holman H. Self-management education: history, definition, outcomes, and mechanisms. Ann Behav Med 2003;26:1-7.

4 Spathis A, Booth S, Moffat C, et al. The breathing, thinking, functioning clinical model: a proposal to facilitate evidence-based breathlessness management in chronic respiratory disease. NPJ Prim Care Respir Med 2017;27:27.

5 Bausewein C, Schunk M, Schumacher P, et al. Breathlessness services as a new model of support for patients with respiratory disease. Chron Respir Dis 2018;15:48-59.

6 Brighton LJ, Miller S, Farquhar M, et al. Holistic services for people with advanced disease and chronic breathlessness: a systematic review and meta-analysis. Thorax 2019;74:270-81.

7 Bausewein C, Schumacher P, Bolzani A. Integrated breathlessness services for people with chronic conditions. Curr Opin Support Palliat Care 2018;12:227-31.

8 Farquhar MC, Prevost AT, McCrone P, et al. The clinical and cost effectiveness of a breathlessness intervention service for patients with advanced non-malignant disease and their informal carers: mixed findings of a mixed method randomised controlled trial. Trials 2016;17:185.

9 Tong A, Sainsbury P, Craig J. Consolidated criteria for reporting qualitative research (COREQ): a 32-item checklist for interviews and focus groups. Int J Qual Health Care 2007;19:349-57.

10 Mahler DA, Wells CK. Evaluation of clinical methods for rating dyspnea. Chest 1988;93:580-6.

11 Smith TA, Roberts MM, Cho J-G, et al. Protocol for a single-blind, randomized, parallel-group study of a nonpharmacological integrated care intervention to reduce the impact of breathlessness in patients with chronic obstructive pulmonary disease. Palliat Med Rep 2020;1:296-306.

12 Guyatt GH, Berman LB, Townsend M, et al. A measure of quality of life for clinical trials in chronic lung disease. Thorax 1987;42:773-8.

13 Luckett T, Roberts MM, Smith T, et al. Patient perspectives on how to optimise benefits from a breathlessness service for people with COPD. NPJ Prim Care Respir Med 2020;30:1-6.

14 Malterud K, Siersma VD, Guassora AD. Sample size in qualitative interview studies: guided by information power. Qual Health Res 2016;26:1753-60.

15 Bradley EH, Curry LA, Devers KJ. Qualitative data analysis for health services research: developing taxonomy, themes, and theory. Health Serv Res 2007;42:1758-72.

16 Farquhar MC, Prevost AT, McCrone P, et al. Is a specialist breathlessness service more effective and cost-effective for patients with advanced cancer and their carers than standard care? Findings of a mixed-method randomised controlled trial. BMC Med 2014;12:194.

17 Hutchinson A, Barclay-Klingle N, Galvin K, et al. Living with breathlessness: a systematic literature review and qualitative synthesis. Eur Respir J 2018;51:1701477. doi:10.1183/13993003.01477-2017

18 Farver-Vestergaard I, O'Toole MS, O'Connor M, et al. Mindfulnessbased cognitive therapy in COPD: a cluster randomised controlled trial. Eur Respir J 2018;51:1702082.

19 Baraniak A, Sheffield D. The efficacy of psychologically based interventions to improve anxiety, depression and quality of life in COPD: a systematic review and meta-analysis. Patient Educ Couns 2011;83:29-36.

20 Stoop CH, Nefs G, Pommer AM, et al. Effectiveness of a stepped care intervention for anxiety and depression in people with diabetes, asthma or COPD in primary care: a randomized controlled trial. J Affect Disord 2015;184:269-76.

21 Early F, Wellwood I, Kuhn I, et al. Interventions to increase referral and uptake to pulmonary rehabilitation in people with COPD: a systematic review. Int J Chron Obstruct Pulmon Dis 2018;13:3571.

22 Ma R-C, Yin Y-Y, Wang Y-Q, et al. Effectiveness of cognitive behavioural therapy for chronic obstructive pulmonary disease patients: a systematic review and meta-analysis. Complement Ther Clin Pract 2020;38:101071.

23 Yohannes AM, Chen W, Moga AM, et al. Cognitive impairment in chronic obstructive pulmonary disease and chronic heart failure: a systematic review and meta-analysis of observational studies. J Am Med Dir Assoc 2017;18:451.e1-e11.

24 Frost J, Garside R, Cooper C, et al. A qualitative synthesis of diabetes self-management strategies for long term medical outcomes and quality of life in the UK. BMC Health Serv Res 2014;14:348.

25 Audulv Åsa. The over time development of chronic illness selfmanagement patterns: a longitudinal qualitative study. BMC Public Health 2013;13:452.

26 Chand SP, Grossberg GT. How to adapt cognitive-behavioral therapy for older adults. Current psychiatry 2013;12:10-15.

27 Pinnock $\mathrm{H}$, Kendall M, Murray SA, et al. Living and dying with severe chronic obstructive pulmonary disease: multi-perspective longitudinal qualitative study. BMJ 2011;342:d142.

28 Frank A. The wounded storyteller: body, illness and ethics. Chicago: University of Chicago Press, 1995.

29 Selzler A-M, Moore V, Habash R, et al. The relationship between self-efficacy, functional exercise capacity and physical activity in people with COPD: a systematic review and meta-analyses. COPD 2020;17:452-61

30 Hosseinzadeh $\mathrm{H}$, Shnaigat M. Effectiveness of chronic obstructive pulmonary disease self-management interventions in primary care settings: a systematic review. Aust J Prim Health 2019;25:195-204.

31 Ansari S, Hosseinzadeh H, Dennis S, et al. Activating primary care COPD patients with multi-morbidity through tailored selfmanagement support. NPJ Prim Care Respir Med 2020;30:12.

32 Donesky-Cuenco D, Chyall L, Nguyen HQ. Improvements in selfefficacy for walking and managing shortness of breath in patients with COPD are sustained for one year during a dyspnea selfmanagement program. A27 advances in pulmonary rehabilitation. American Thoracic Society, 2010: A1213-A13.

33 Korpershoek Y, Vervoort S, Nijssen L, et al. Factors influencing exacerbation-related self-management in patients with COPD: a qualitative study. Int J Chron Obstruct Pulmon Dis 2016:11:2977.

34 Nyberg A, Wadell K, Lindgren $\mathrm{H}$, et al. Internet-based support for self-management strategies for people with COPD-protocol for a controlled pragmatic pilot trial of effectiveness and a process evaluation in primary healthcare. BMJ Open 2017;7:e016851.

35 Garcia MV, Luckett T, Johnson M, et al. The roles of dispositional coping style and social support in helping people with respiratory disease cope with a breathlessness crisis. J Adv Nurs 2019;75:1953-65.

36 Hibbard JH, Stockard J, Mahoney ER, et al. Development of the patient activation measure (PAM): conceptualizing and measuring activation in patients and consumers. Health Serv Res 2004;39:1005-26.

37 Robinson S, Kissane DW, Brooker J, et al. A review of the construct of Demoralization: history, definitions, and future directions for palliative care. Am J Hosp Palliat Care 2016;33:93-101. 